\title{
MELHORIAS OPERACIONAIS PARA REDUÇÃO DO CONSUMO ENERGÉTICO DO FORNO DE PLACAS *
}

\author{
Eduardo Amado Marconato ${ }^{1}$ \\ Carlos Alberto A de Souza ${ }^{2}$ \\ Marcos Roberto Soares da Silva ${ }^{3}$
}

\section{Resumo}

Na usina siderúrgica de Cubatão da Usiminas, o forno de reaquecimento de placas do LTQ2 utilizava como gás combustível a composição de gases de coqueria, alto forno e natural. A partir da interrupção da produção das áreas primárias (Redução e Aciaria) em Cubatão, o equipamento precisou ser adaptado para uso exclusivo do gás natural como gás combustível. Além das adequações feitas nos sistemas de controle de combustão foram adotadas ações para redução do consumo de combustível como desenvolvimento de novos procedimentos de acendimento do forno, reduzindo o número de queimadores ligados visando aproveitar melhor o calor gerado pela combustão do gás natural. O sistema de combustão foi reconfigurado, permitindo reduzir a temperatura da zona de pré-aquecimento e o tempo de permanência no forno, com isso a economia alcançada no consumo térmico superior a $7 \%$.

Palavras-chave: Forno de Reaquecimento; Gás Natural; Consumo de Combustível.

\section{OPERATIONAL IMPROVEMENTS IN THE REHEATING FURNACE TO DECREASE FUEL CONSUMPTION}

\begin{abstract}
The mixed gas used to reheat slabs of Usiminas's Cubatão HSM2 furnace was blended by coke oven gas, blast furnace gas and natural gas. Due the discontinuance of production in the primary areas in Cubatão, the furnace was adapted to use natural gas as a dedicated fuel gas. In addition to the adjustments of combustion control of the furnace, some operational practices were taken to optimize the operational costs depending of production demand, like decrease fuel consumption, development of new operational standards, number of burners in operation during heating curves. The combustion control has been reconfigured to new standards, allowing to decrease the temperature of the preheating zones and the slab residence time, allowing an overall reduction of specific fuel consumption higher than $7 \%$.
\end{abstract}

Keywords: Slab Reheating Furnace; Natural Gas; Fuel Consumption

1 Engenheiro de Materiais, Mestre em Engenharia de Materiais, Engenheiro de Produção, Laminação a Quente, Usiminas, Cubatão, São Paulo - Brasil.

2 Técnico Metalurgista, Assistente Técnico Industrial, Laminação a Quente, Usiminas, Cubatão, São Paulo - Brasil.

3 Engenheiro Metalurgista, Gerente Suporte Técnico das Laminações, Laminação a Quente, Usiminas, Cubatão, São Paulo - Brasil. 


\section{INTRODUÇÃO}

$\mathrm{Na}$ laminação de tiras a quente, uma das etapas principais para produção de bobinas é o processo de reaquecimento de placas de aço até a temperatura necessária para garantir a transformação da placa em bobina a quente, onde a presença de elementos químicos microligante na matriz do aço é importante para o aumento da resistência mecânica para o produto final, necessitando em linhas gerais, aumentar a temperatura dos fornos de reaquecimento ou o tempo de permanência da placa dentro do forno. Como esses requisitos impactam diretamente no custo de transformação do produto, eles devem ser alcançados por projetos de melhoria contínua de produtividade e redução de consumo energético, sendo este um dos principais itens que impactam no custo de produção de uma linha de tiras a quente.

O consumo de energia térmica de um forno de reaquecimento corresponde a quantidade de energia gerada pela combustão de um ou mais gases combustíveis dentro forno, utilizado para reaquecer todas as placas dentro do forno, desde o momento do seu enfornamento até atingir a temperatura objetivada de desenfornamento, respeitando as curvas de aquecimento de cada tipo de material e assim, visando sempre o equilíbrio entre produtividade do laminador e qualidade final do produto laminado $[1,2]$. Desta forma, a energia térmica despendida para o aquecimento das placas, está relacionada à competitividade da empresa, por meio do custo final por tonelada de bobina produzida. Segundo Teixeira, fornos de reaquecimento são responsáveis por até $15 \%$ do consumo total de combustível numa usina siderúrgica integrada [3].

Desde o início da operação do laminador de tiras a quente em março de 2012, o desempenho do forno de reaquecimento apresenta uma evolução expressiva na redução do consumo de combustível. A partir da pausa de produção das áreas primárias na usina de Cubatão no final de 2015, a disponibilidade de gás de alto forno (BFG) e gás de coqueria (COG) foi interrompida para compor a mistura de gases combustíveis juntamente com o gás natural (GN) para uso do forno de reaquecimento do LTQ2, o equipamento precisou ser adaptado para uso exclusivo de gás natural, principalmente em relação aos itens de controle de vazão do sistema de instrumentação do forno e adequação das válvulas de gás para o poder calorífico do gás natural puro.

Em função da demanda do mercado consumidor de aço no Brasil diminuir, novas alternativas foram adotadas para adequar ao novo cenário de produção do laminador, especialmente em relação ao planejamento da produção do laminador de maneira agrupada, permitindo reduzir o consumo de combustível durante paradas programadas. Novos procedimentos de acendimento do forno foram desenvolvidos visando minimizar perdas térmicas durante o aquecimento dos refratários internos, além da redução da quantidade de queimadores ativos visando aproveitar melhor o calor gerado pela combustão do gás natural e após a reconfiguração do sistema de combustão, foi possível trabalhar com temperatura da zona de pré-aquecimento reduzidas, permitindo também operar com tempo de permanência das placas menores. 
Todas essas novas oportunidades desenvolvidas em Cubatão para reduzir o consumo de energia térmica fortalece a posição da Usiminas no mercado de laminados a quente através de uma melhor competitividade em custos de produção. O presente trabalho tem como objetivo apresentar os principais resultados alcançados para a otimização do processo de laminação, visando à redução do consumo específico de combustível do forno de reaquecimento de placas e ao aumento de produtividade do laminador.

\section{MATERIAIS E MÉTODOS}

O forno de reaquecimento de placas do LTQ de Cubatão é do tipo walking beam (vigas caminhantes), com capacidade nominal de $400 \mathrm{t} / \mathrm{h}$, possuindo controle de aquecimento por modelamento matemático visando otimizar as curvas de aquecimento de cada material com o consumo de combustível. $\mathrm{O}$ modelo de reaquecimento é realizado dinamicamente, em tempo real, cujo principal objetivo é realizar o cálculo da distribuição de temperatura em cada placa no interior do forno. Isso é conseguido através da solução de equações matemáticas complexas, denominadas equações diferenciais de Fourier, que calculam a distribuição de aquecimento das placas dentro do forno [4].

O modelo matemático atua no sistema de controle de nível 2 do forno com as temperaturas visadas de trabalho em função do ritmo de desenfornamento médio do material. A lógica de controle realiza o cálculo dos valores das temperaturas objetivadas de todas as zonas de aquecimento, através da resposta do modelo da temperatura calculada de cada placa, prevendo o atendimento da temperatura visada da placa no final de cada fase do forno. O objetivo da lógica de controle é realizar o aquecimento de cada placa dentro do forno assim que a temperatura objetivada no final de cada fase do forno for atingida, desta forma otimizando consumo de energia térmica $[1,4]$.

As análises relacionadas ao consumo de energia térmica foram realizadas através dos dados reais armazenados no banco de histórico do equipamento, desde o início da produção em escala comercial até o $2^{\circ}$ trimestre de 2017, correlacionando com produtividade do laminador, taxa de ocupação e agrupamento da produção.

A quantidade de energia consumida pela queima do gás natural esta intimamente relacionada a demanda de mercado e ao mix de produtos previstos programados mensalmente, sendo necessária uma planejamento diário de produção para que toda a cadeia produtiva, desde a aquisição e recebimento de placas de aço no mercado fornecedor até o escoamento das bobinas para os clientes internos e externos.

Uma das maneiras adequadas para controlar o consumo de combustível do forno é subdividindo em parcelas que possam ser mensuradas com ajuda de softwares de monitoramento e que estejam ligadas a produção do laminador em um determinado período conforme exemplificado na tabela 1. 
Tabela 1. Fatores que impactam o consumo de combustível.

\begin{tabular}{ll}
\hline \multicolumn{1}{c}{$\begin{array}{c}\text { Acompanhamento } \\
\text { Operacional }\end{array}$} & \multicolumn{1}{c}{ Fatores de Impacto } \\
\hline 1. Acendimento do Forno & - Quantidade de zonas em operação \\
& - Duração da curva projetada \\
& - Temperatura para encharque dos refratários \\
\hline 2. Consumo Efetivo & - Produtividade do laminador \\
& - Tempo de permanência \\
& - Parâmetros de aquecimento \\
& - Dimensional de produtos \\
& - Requisitos metalúrgicos, etc \\
\hline 3. Paradas de Produção & - Trocas de cilindros de laminação \\
& - Manutenção Preventiva \\
& - Paradas em emergência, etc \\
\hline
\end{tabular}

\section{RESULTADOS E DISCUSSÃO}

\subsection{Evolução do Consumo Médio}

A figura 1 ilustra a evolução do indicador de consumo específico médio de combustível do forno desde o start up do LTQ2 em meados de 2012 até o primeiro semestre de 2017, juntamente com o nível de ocupação do laminador a quente. Pode ser observado que o consumo anual vem reduzindo continuamente, alcançando patamares inferiores a $360 \mathrm{Mcal} / \mathrm{t}$ em 2017, onde em particular em abril de 2017, o melhor resultado histórico mensal foi atingido de $341 \mathrm{Mcal} / \mathrm{t}$, incluindo a energia consumida para acendimento do forno e paradas programadas ou em emergência do laminador. Este resultado é bastante expressivo operacionalmente para o nível de ocupação do laminador relativamente baixo devido a queda do consumo de aço.

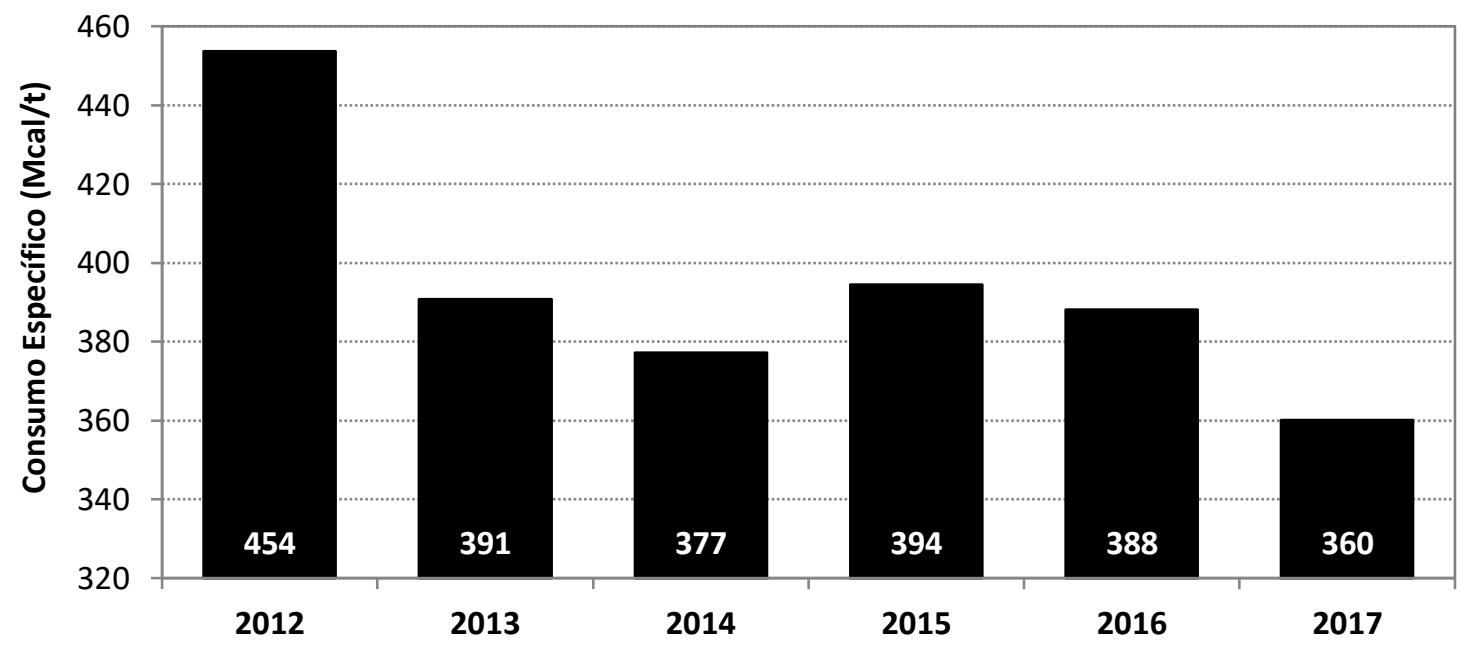

Figura 1. Evolução do consumo específico de combustível do forno de placas.

Diversos fatores influenciaram para alcançar o resultado alcançado em 2017, onde serão discutidos abaixo os principais responsáveis itens que levaram a redução do consumo de combustível. 


\subsection{Acendimento do Forno}

Como já mencionado no capitulo 2, a energia consumida para acendimento do forno de placas é um ponto importante para ser acompanhado operacionalmente pois representa uma parcela expressiva no resultado final de cada período. A duração e os patamares de temperatura são pontos chave para adequar uma curva de acendimento em relação a eventuais reparos dos refratários, pois impacta diretamente na vida útil dos refratários do forno. Outro fator chave que foi adotado e que impacta diretamente no consumo durante o acendimento é a estratégia para realizar a ignição do forno, principalmente em relação a quantidade de zonas acesas e queimadores ativos, onde foi possível reduzir em $50 \%$ a quantidade de zonas acesas e em até $60 \%$ a quantidade de queimadores ativos por zona.

A figura 2 apresenta a evolução decrescente no impacto do consumo de energia térmica no consumo trimestral a partir de 2016 até o presente momento, onde foi possível reduzir o impacto de 5,6 para $1,3 \%$ da curva de acendimento do forno, representando uma redução relativa de aproximadamente $77 \%$.

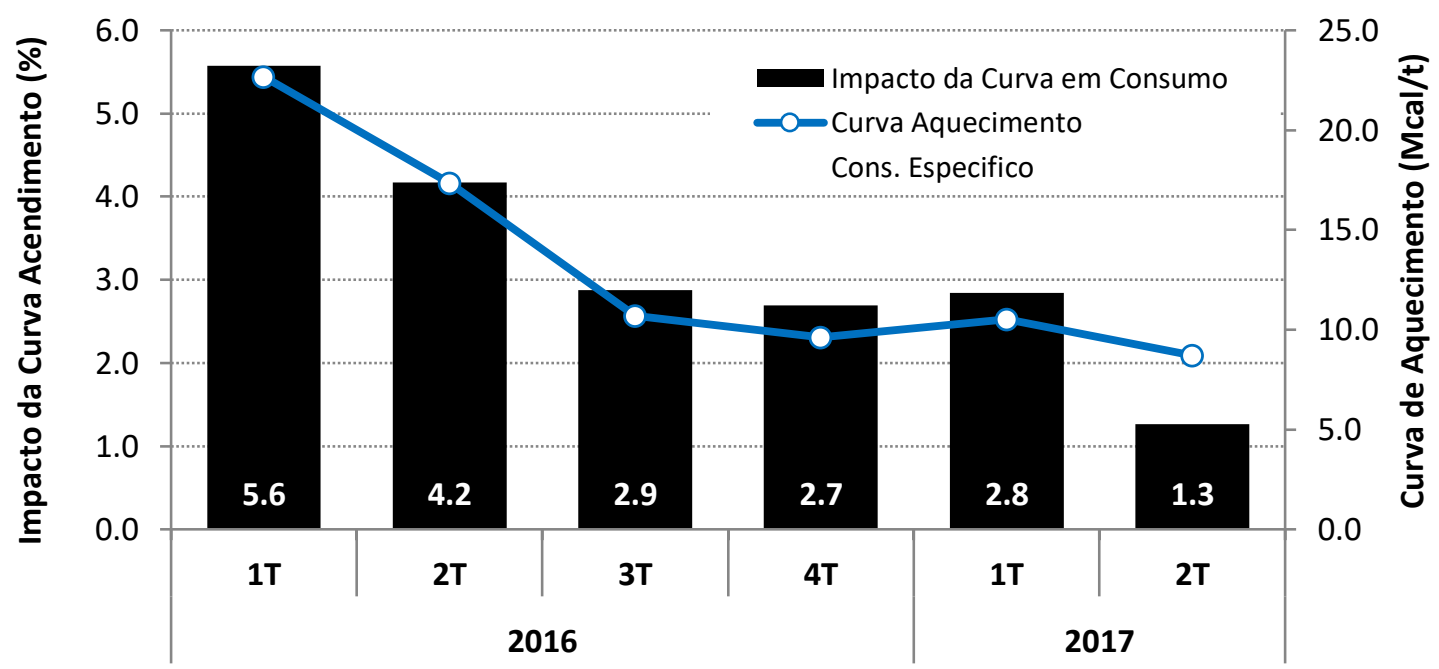

Figura 2. Impacto da curva de aquecimento no consumo específico.

\subsection{Consumo Efetivo}

\subsubsection{Produtividade Efetiva}

Um dos principais indicadores de controle da laminação a quente é a produtividade efetiva, pois mede a quantidade de material processado por hora. Este indicador é sensível aos requisitos dimensionais e metalúrgicos dos produtos que estão em carga no forno, como o peso médio das placas, tempo de permanência do material e o tipo de programa de laminação que as placas foram sequenciadas para a produção.

A participação de materiais críticos em relação a necessidade de aquecimento diferenciado aumenta continuamente em função do mercado consumidor da Usiminas e aos novos desenvolvimentos de produtos realizados internamente em Cubatão, sendo assim novas alternativas de sequenciamento de 
placas foram estabelecidas e a revisão dos tempos de permanência objetivados para cada classe de material também foram alteradas visando minimizar as perdas de produtividade. A produtividade do forno de placas afeta diretamente o consumo específico de combustível, pois no caso dos materiais que demandam maior tempo de forno, acabam consumindo maior quantidade de energia térmica por tonelada produzida. A figura 3 ilustra a evolução do indicador de produtividade do laminador, onde no $2^{\mathrm{o}}$ Trimestre de 2017 foi possível atingir a marca trimestral de $299 \mathrm{t} / \mathrm{h}$ mesmo com uma maior participação no mix dimensional restritivo, principalmente para materiais de autopeças.

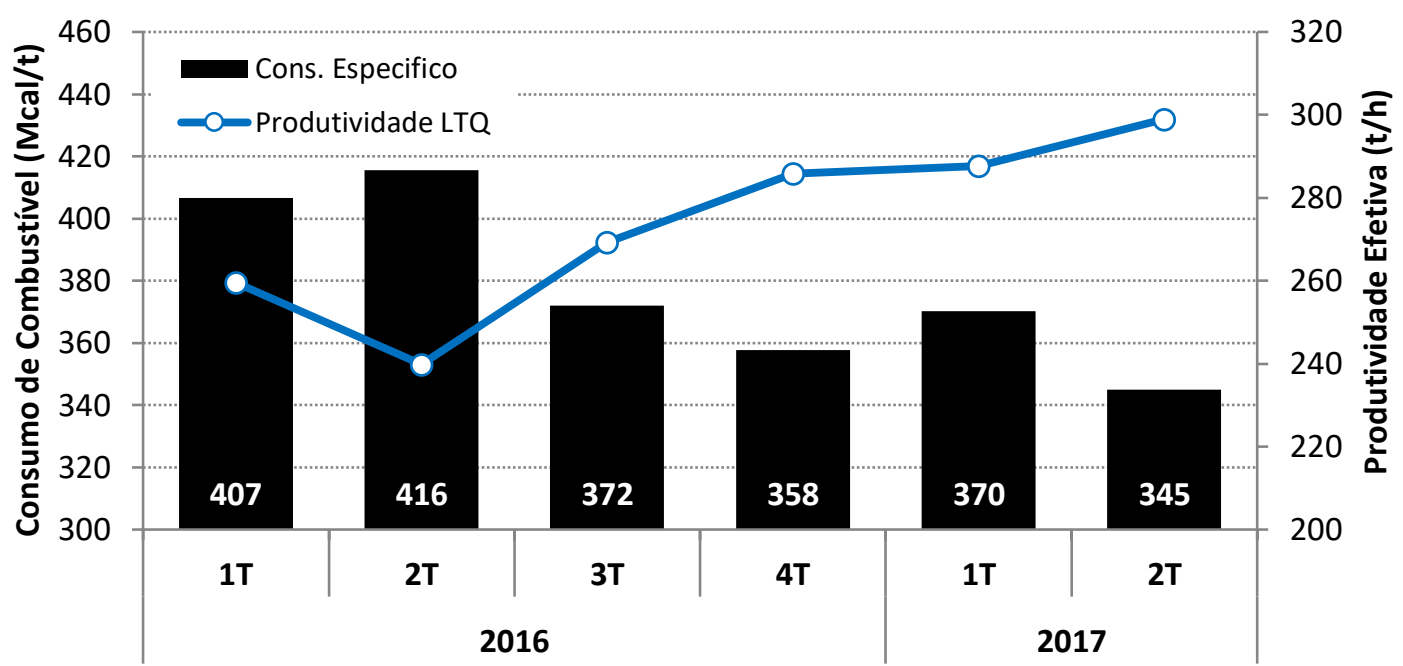

Figura 3. Consumo Combustível vs Produtividade Efetiva.

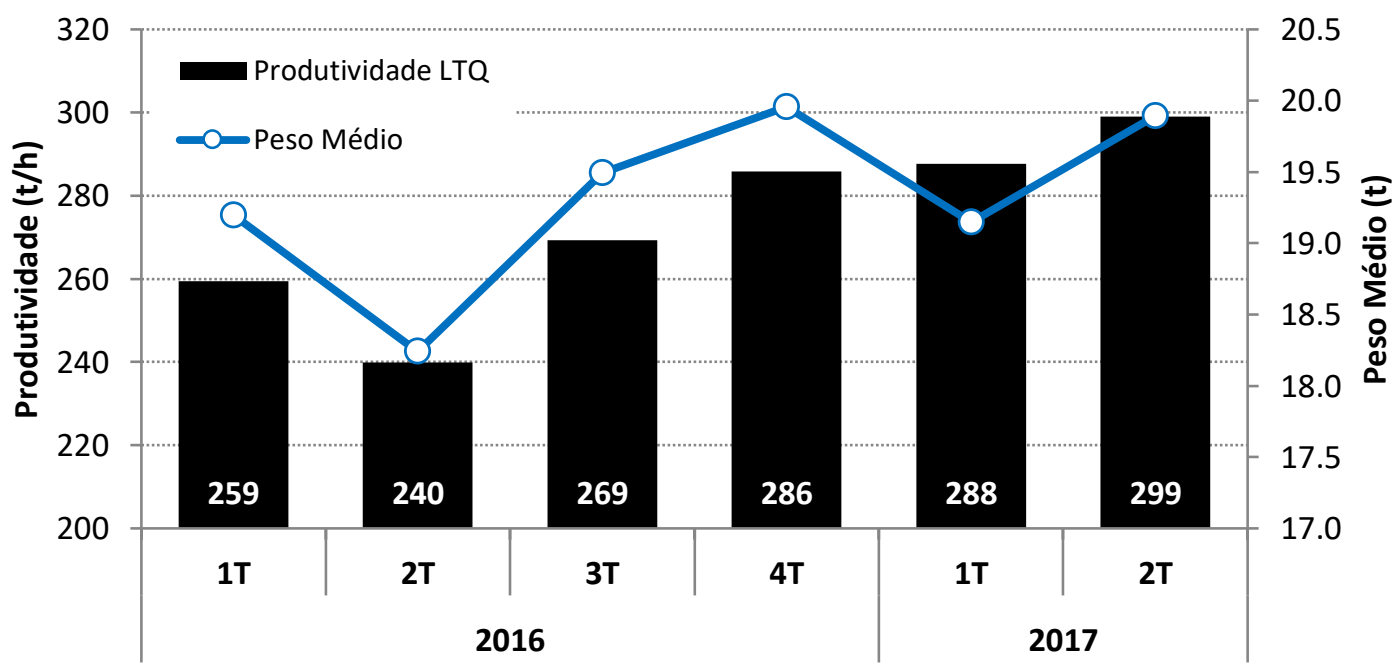

Figura 4. Produtividade Efetiva vs Peso Médio de Bobina.

Comparando as figuras 3 e 4 podemos observar que o efeito do peso médio no aumento da produtividade não é tão significativo em 2017 quanto ao longo de 2016, reflexo das alterações das tabelas de tempo de permanência padrão e do sequenciamento de programação, principalmente pelo agrupamento preferencial de placas com espessura acima de 240mm. 


\subsubsection{Parâmetros de Aquecimento}

O trabalho de otimização dos parâmetros de forno para todas as famílias de aquecimento se intensificou a partir do $4^{\circ}$ Trimestre de 2016, pois conforme mostrado na figura 5, a temperatura média objetivada de desenfornamento vem gradativamente sendo elevada devido principalmente ao aumento da participação de materiais com dimensionais cada vez mais desafiadores para a laminação (extrafinos / extra-largos), necessitando de temperaturas de desenfornamento cada vez maiores para o processamento adequado nas cadeiras acabadoras do LTQ2. Desta forma, mecanismos alternativos para controle das temperaturas internas do forno foram adotados principalmente visando aumentar a eficiência térmica dos gases queimados e visando reduzir a temperatura das zonas e maximizar o uso da região pré-aquecimento (sem queimadores) do forno.

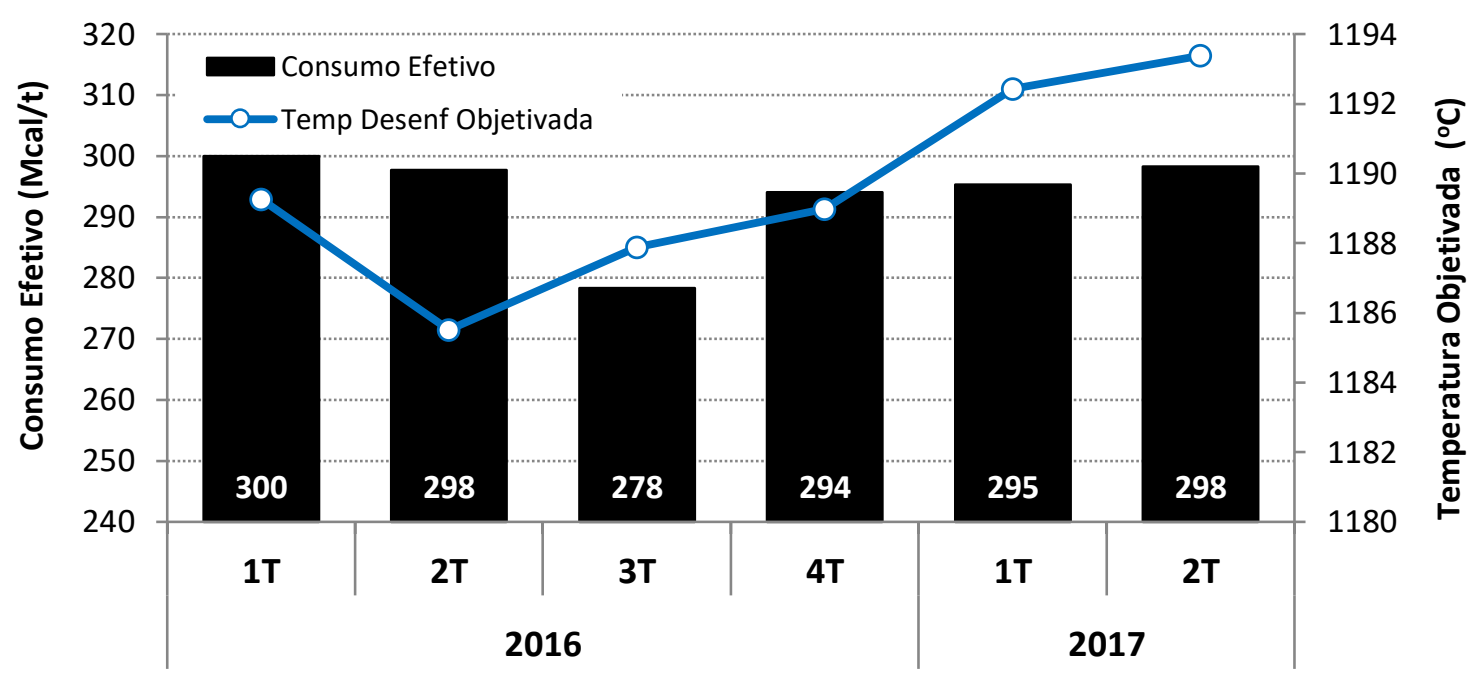

Figura 5. Impacto da curva de aquecimento no consumo específico.

Pode-se observar no gráfico da figura 5 que o consumo efetivo do forno apresentou forte redução até o $3^{\circ}$ trimestre de 2016, chegando a resultados inéditos de $278 \mathrm{Mcal} / \mathrm{t}$ para uma referência base do equipamento de $300 \mathrm{Mcal} / \mathrm{t}$, ou seja, uma redução de 7,3\%. Entretanto, conforme já mencionado anteriormente, o enobrecimento do mix impacta negativamente o consumo de combustível, porém comparando-se 0 resultado do $2^{\circ} \mathrm{T} / 2016$ com $2^{\circ} \mathrm{T} / 2017$, temos 0 mesmo comportamento de consumo efetivo para uma elevação de $7^{\circ} \mathrm{C}$ no $2^{\circ} \mathrm{T} / 2017$ da temperatura média objetivada. Esse resultado alcançado indica que as ações tomadas operacionalmente de controle de temperatura das zonas de aquecimento mostraram-se efetivas em relação ao consumo de combustível.

\section{CONCLUSÃO}

Este trabalho teve como objetivo apresentar as principais atividades desenvolvidas visando reduzir o consumo específico de energia térmica do forno de reaquecimento de placas da linha de tiras a quente de Cubatão/SP, onde o benefício alcançado com as ações de melhoria operacional foi a redução contínua do consumo específico de combustível superando em $7 \%$ quando comparado ao início de 2016. 


\section{Agradecimentos}

Aos supervisores de turno e operadores da laminação de tiras a quente de Cubatão pela dedicação e zelo para garantir que os procedimentos operacionais fossem integralmente respeitados. Todo 0 corpo técnico das áreas de instrumentação, engenharia, planejamento da programação e energia e utilidades que colaboram para o êxito do trabalho.

\section{REFERÊNCIAS}

1 Marconato EA, De Castro SF, Silva MRS. Evolução do consumo de combustível dos fornos de reaquecimento de placas da linha de tiras a quente da Usiminas. 52은 Seminário de Laminação - Processos e Produtos Laminados e Revestidos, Rio de Janeiro. Ago. 2015

2 Marconato EA, Coscia FP, Guia JRP, Silva MRS. Redução do consumo de combustíveis dos fornos de reaquecimentos de placas da Usiminas Cubatão. 47음 Seminário de Laminação - Processos e Produtos Laminados e Revestidos, Belo Horizonte. Out. 2010.

3 Teixeira, MH, Jota, FG, Carmo, RA, Oliveira, CAS. Aplicação de controle avançado nos fornos de reaquecimento de placas da linha de tiras a quente da Usiminas. Tecnologia em Metalurgia e Materiais, São Paulo, v.4, n.1, p. 30-35, jul.-set. 2007.

4 Magalhães, MM, Marconato EA, Guia JRP, Silva MRS. Novo laminador de tiras a quente da Usiminas Cubatão. 47ํㅗㄴ Seminário de Laminação - Processos e Produtos Laminados e Revestidos, Belo Horizonte. Out. 2010. 